\title{
Rocky Mountain Spotted Fever
}

National Cancer Institute

\section{Source}

National Cancer Institute. Rocky Mountain Spotted Fever. NCI Thesaurus. Code

C128410.

An infection that is caused by Rickettsia rickettsii, which is transmitted to humans from infected ticks; it is characterized by the sudden onset of fever, headache, and myalgia, followed by rash that usually begins peripherally. 